\title{
System Integration of the Horizontal-Axis Wind Turbine: The Design of Turbine Blades with an Axial-Flux Permanent Magnet Generator
}

\section{Chi-Jeng Bai ${ }^{1}$, Wei-Cheng Wang ${ }^{1,2, *}$, Po-Wei Chen ${ }^{1}$ and Wen-Tong Chong ${ }^{3,4}$}

1 Department of Aeronautics and Astronautics, National Cheng Kung University, Tainan 70101, Taiwan; E-Mails: chijeng.bai@gmail.com (C.-J.B.); wishfly227@gmail.com (P.-W.C.)

2 Research Center for Energy Technology and Strategy, National Cheng Kung University, Tainan 70101, Taiwan

3 Department of Mechanical Engineering, Faculty of Engineering, University of Malaya, Kuala Lumpur 50603, Malaysia; E-Mail: chong_wentong@um.edu.my

4 Centre for Energy Sciences, Faculty of Engineering, University of Malaya, Kuala Lumpur 50603, Malaysia

* Author to whom correspondence should be addressed; E-Mail: wilsonwang@mail.ncku.edu.tw; Tel.: +886-6-275-7575 (ext. 63628); Fax: +886-6-238-9940.

External Editor: Frede Blaabjerg

Received: 5 August 2014; in revised form: 30 October 2014 / Accepted: 14 November 2014 / Published: 21 November 2014

Abstract: In designing a horizontal-axis wind turbine (HAWT) blade, system integration between the blade design and the performance test of the generator is important. This study shows the aerodynamic design of a HAWT blade operating with an axial-flux permanent magnet (AFPM) generator. An experimental platform was built to measure the performance curves of the AFPM generator for the purpose of designing the turbine blade. An in-house simulation code was developed based on the blade element momentum (BEM) theory and was used to lay out the geometric shape of the turbine blade, including the pitch angle and chord length at each section. This simulation code was combined with the two-dimensional (2D) airfoil data for predicting the aerodynamic performance of the designed blades. In addition, wind tunnel experiments were performed to verify the simulation results for the various operating conditions. By varying the rotational speeds at four wind speeds, the experimental and simulation results for the mechanical torques and 
powers presented good agreement. The mechanical power of the system, which maximizes at the best operating region, provided significant information for designing the HAWT blade.

Keywords: wind turbine; horizontal-axis wind turbine (HAWT); axial-flux permanent magnet (AFPM) generator; blade element momentum (BEM) theory; airfoil; wind tunnel experiment

\section{Introduction}

A small-scale horizontal-axis wind turbine (HAWT) system which provides less than $10 \mathrm{~kW}$ output is relatively simpler than large-scale ones in both design and construction because there is no gear box and pitch control system, but traditionally it has drawn little attention due to its low power capacity and economic concerns [1-3]. Nonetheless, to have an effective HAWT system, some practical problems still exist in the system integration of the force and moment/torque distributions between the turbine blades and the electric generators.

Recently, studies on small-scale HAWT systems are focused on the developments in the fields of aerodynamics, mechanical/electrical engineering, control technology, and electronics. The optimal HAWT blade shape design and the performance analysis, characterized as parts of aerodynamics, are intensively analyzed using the blade element momentum (BEM) theory [4-10]. This models turbine blades as a set of isolated two-dimensional (2D) airfoils and then performs an integration to find the thrust and torque. Goundar and Ahmed [4] designed a 3-bladed horizontal-axis tidal current turbine (HATCT) blade with a $10 \mathrm{~m}$ diameter using the BEM theory. This theory is applied to predict the aerodynamic performance, resulting in the maximum efficiency of $47.6 \%$ at the rated wind speed of $2 \mathrm{~m} / \mathrm{s}$ and tip speed ratio (TSR) of 4. Lanzafame and Messina [9] built a mathematical model through BEM theory to calculate the aerodynamic performance for the NREL Phase III turbine. The lift and drag coefficient curves of the wind turbine system were successfully characterized for the evaluation of the axial and angular induction factors. Dai et al. [10] has also predicted the aerodynamic loads for the MW scale HAWT blade using the BEM theory. This model was modified by Prandtl and Buhl based on the B-L semi-empirical dynamic stall (DS) model, developed for calculating the NACA63-4xx airfoil. The DS model is currently appropriate for engineering applications. Hirahara et al. [11] and Koki et al. [12] have proposed a method for experimentally determining the mechanical torque generated from the turbine blade using a torque transducer installed between the turbine blade and the electric generator inside a wind tunnel. Hsiao et al. [5] has designed a HAWT blade with a radius of $0.36 \mathrm{~m}$ using the improved BEM theory and tested the aerodynamic performance in a wind tunnel. Previous studies related to the aerodynamic tests have provided useful information for measuring the turbine blade performance including the behavior of airfoils, blades and wakes, which helped not only in understanding the aerodynamic characteristics, but also the mathematical models [13-15].

Recently, variable-speed HAWT systems have gradually replaced constant-speed ones, which have fairly low system efficiencies at most of the wind speeds. To improve the system efficiency, many modern wind turbine systems adapt the variable-speed systems with an electronic control system $[16,17]$. For example, the small-scaled HAWT system takes advantage of the variable-speed 
operation with suitable control rules such as maximum power point tracking (MPPT) approach for reaching the maximum system efficiency at each set of the operating conditions [18-22].

The doubly-fed induction generator (DFIG) and permanent magnet synchronous generator (PMSG) have become more and more popular in HAWT system applications. Generally, the DFIGs are mostly used in the large-scale HAWT systems due to their large size and complex components. Grid-fault ride-through control is also difficult for DFIGs since the stator and rotor are both connected to the electronic control system [16,23,24]. Compared with the radial-flux permanent magnet (RFPM) machine, the axial-flux permanent magnet (AFPM) machine has adjustable air-gap, better efficiency, and higher torque-to-weight ratio [25]. The size of the AFPM machine, commonly including a main shaft with one stator (coil) and two rotors (PM), is small due to its fewer components compared with the RFPM machine, making it suitable for a small-scale HAWT system [26]. Few studies have been carried out to test the performance of a HAWT with the AFPM generator.

By many accounts, the system integration between the turbine blades and the electric generator is rarely considered as one of the turbine blade design procedures in the previous studies. Here, integration of the turbine blade design and the performance of the generator is carried out, as shown in Figure 1. The structure of the study is laid out as follows: in Section 2 the developed simulation code from the BEM theory to design the HAWT blade and predict its aerodynamic performance is described. In Section 3, a ready-made AFPM generator with a coreless stator is discussed in detail and its performance curve obtained using an experimental platform is illustrated. Section 4 describes the design of a HAWT blade using the developed simulation code based on the electrical performance curves obtained from the APFM generator. Section 5 illustrates the wind tunnel experiments for obtaining the aerodynamic performance of designed turbine blade. The simulation and experimental results are compared and discussed in Section 6.

Figure 1. Flowchart for designing the HAWT turbine blade.

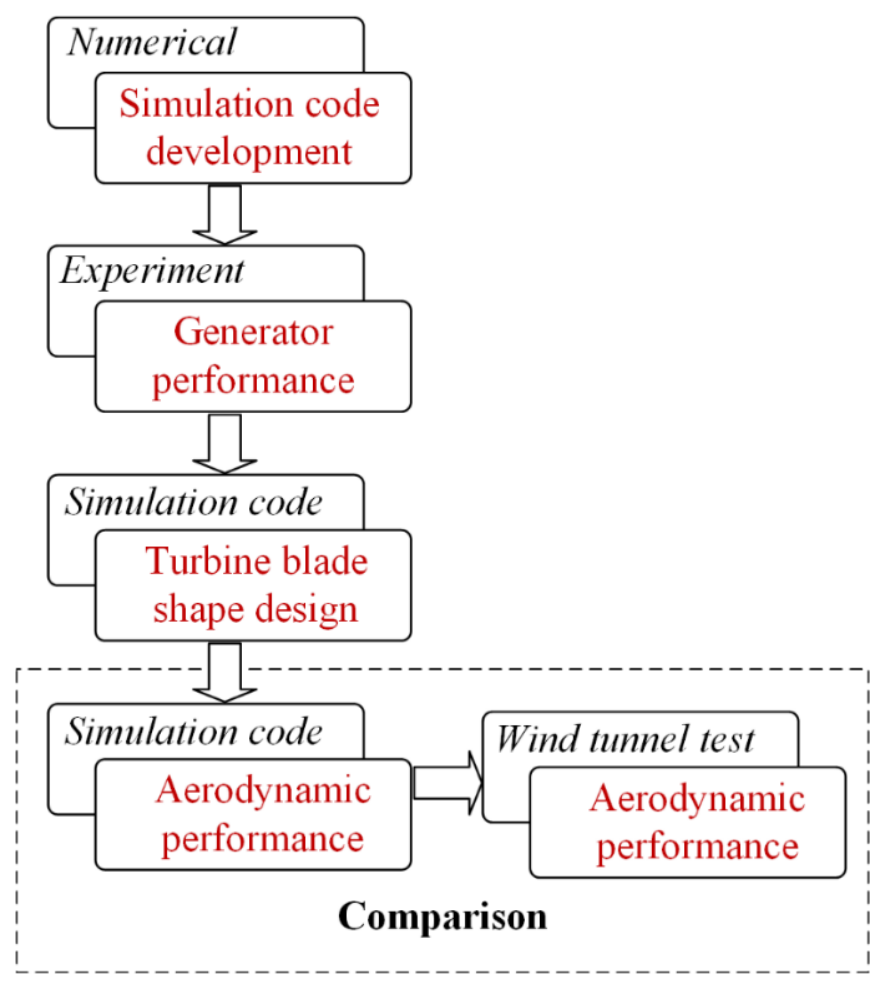




\section{Simulation Code}

In this study, a simulation code [5] based on the BEM theory is developed to lay out the geometric shape of the turbine blade, and furthermore, to predict its aerodynamic performance. This simulation code, which previously has low accuracy on predicting the blade stall region [5], was modified by the Viterna-Corrigan (VC) stall and stall delay models to improve the predictions for the performance.

To obtain the distributions of the chord length for an airfoil and the pitch angle in each of the sections, the following equations are taken into account $[5,27]$ :

$$
\begin{gathered}
c(r)=\frac{8 \pi r}{N_{\mathrm{b}} C_{\mathrm{l}}}\left\{1-\cos \left[\frac{2}{3} \tan ^{-1}\left(\frac{1}{\lambda_{r}}\right)\right]\right\} \\
\theta_{\mathrm{p}}=\frac{2}{3} \tan ^{-1}\left(\frac{1}{\lambda_{r}}\right)-\alpha_{\mathrm{d}}
\end{gathered}
$$

where $r$ is the sectional radius of blade; $N_{\mathrm{b}}$ is the number of blade; $C_{1}$ is the lift coefficient; $\lambda_{r}$ is the local tip speed ratio; and $\alpha_{\mathrm{d}}$ is the designed angle of attack.

Figure 2 displays the relationship between the various velocities, angles and forces on one of the blade sections. In other words, the blade geometries including the chord length and the pitch angle for each of the sections at a particular wind speed are determined using the BEM theory.

Figure 2. Diagram of velocities, angles and forces on one blade.

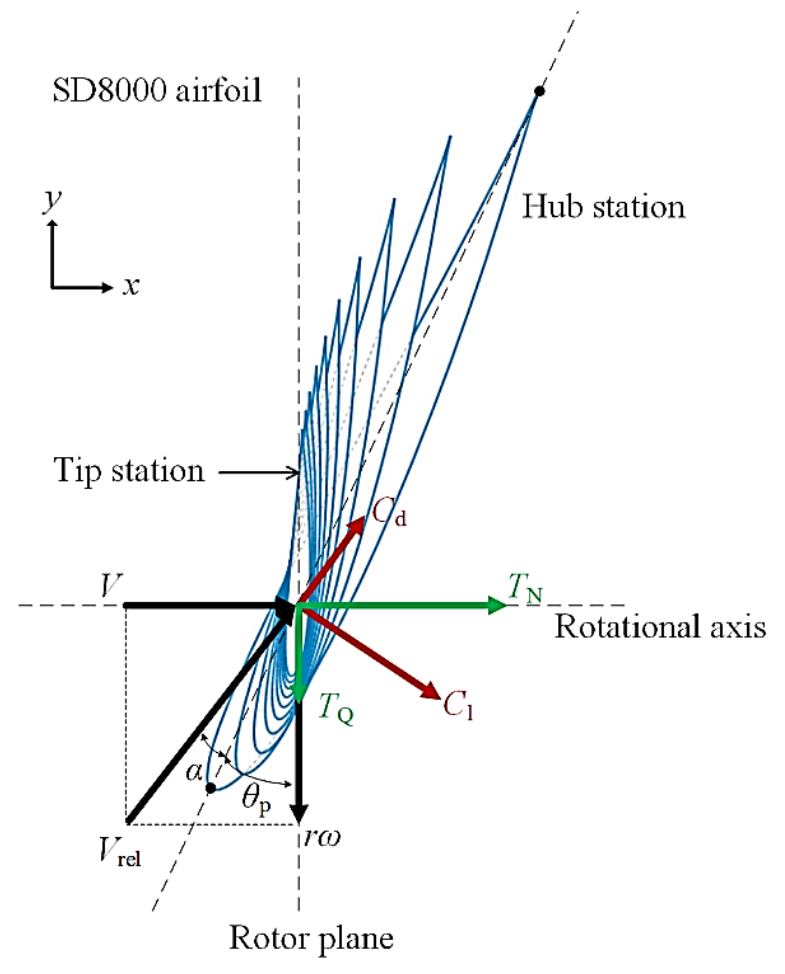

The axial force acting on the blades and torque produced by the blades are given in Equations (3) and (4), respectively, resulting in the power and power coefficient at the turbine blade:

$$
T_{\mathrm{N}}=\sigma \pi \rho \frac{V^{2}(1-a)^{2}\left(C_{\mathrm{l}} \cos \emptyset+C_{\mathrm{d}} \sin \emptyset\right)}{\sin ^{2} \emptyset} r d r
$$

where $V$ is the wind speed; $\rho$ is the air density: 


$$
T_{\mathrm{Q}}=\sigma \pi \rho \frac{V^{2}(1-a)^{2}\left(C_{\mathrm{l}} \sin \emptyset-C_{\mathrm{d}} \cos \emptyset\right)}{\sin ^{2} \emptyset} r^{2} d r
$$

$C_{\mathrm{d}}$ is the drag coefficient; $\varnothing$ is the angle of relative wind; and $\sigma$ and $a$ are the local solidity and axial induction factor, respectively. They are defined as:

$$
\begin{gathered}
\sigma=\frac{N_{b} c(r)}{2 \pi r} \\
a=\frac{\sigma\left(C_{\mathrm{l}} \cos \emptyset+C_{\mathrm{d}} \sin \emptyset\right)}{4 F \sin ^{2} \emptyset+\sigma\left(C_{\mathrm{l}} \cos \emptyset+C_{\mathrm{d}} \sin \emptyset\right)}
\end{gathered}
$$

where $F$ is the tip loss factor described by Prandtl [27], written as:

$$
F=\frac{\pi}{2} \cos ^{-1}\left\{\exp \left[-\left(\frac{N_{\mathrm{s}}}{2} \frac{1-\frac{r}{R}}{\left(\frac{r}{R}\right) \sin \emptyset}\right)\right]\right\}
$$

where $N_{\mathrm{s}}$ and $R$ are the numbers of blade section and the radius of blade, respectively. In the turbulent wake state, it is solved using the empirical relationship between the angle of attack and the thrust coefficient $\left(C_{\mathrm{T}}\right)$ [27], written as:

$$
C_{\mathrm{T}}=\frac{\sigma(1-a)^{2} C_{\mathrm{l}} \cos \emptyset+C_{\mathrm{d}} \sin \emptyset}{\sin ^{2} \emptyset}
$$

If $C_{\mathrm{T}}>0.96$, then the axial induction factor is modified as:

$$
a=\frac{1}{F}\left[0.143+\sqrt{0.0203-0.6427\left(0.889-C_{\mathrm{T}}\right)}\right]
$$

If $C_{\mathrm{T}}<0.96$ then the axial induction factor is solved using Equation (6).

For the application of the HAWT system, either with constant-speed or with variable-speed operation, the aerodynamic parameters are determined based on the airfoil theory. Before the stall angle of attack, the lift and drag coefficients are calculated from the data obtained from wind tunnel experiments [28]. After the stall angle of attack, the Viterna-Corrigan (VC) stall model is applied [29]. The lift and drag coefficients of the VC stall model are written as:

$$
\begin{gathered}
C_{\mathrm{l}}(\alpha)=\frac{1}{2} C_{\mathrm{d}, \max } \sin 2(\alpha)+K_{\mathrm{L}} \cos ^{2}(\alpha) / \sin (\alpha) \\
C_{\mathrm{d}}(\alpha)=C_{\mathrm{d}, \max } \sin ^{2}(\alpha)+K_{\mathrm{D}} \cos (\alpha)
\end{gathered}
$$

where $K_{\mathrm{L}}$ and $K_{\mathrm{D}}$ are represented as:

$$
\begin{gathered}
K_{\mathrm{L}}=\left[C_{\mathrm{l}, \mathrm{s}}-C_{\mathrm{d}, \max } \sin \left(\alpha_{\mathrm{s}}\right)\right] \frac{\sin \left(\alpha_{\mathrm{s}}\right)}{\cos ^{2}\left(\alpha_{\mathrm{s}}\right)} \\
K_{\mathrm{D}}=\frac{C_{\mathrm{l}, \mathrm{s}}-C_{\mathrm{d}, \max } \sin ^{2}\left(\alpha_{\mathrm{s}}\right)}{\cos \left(\alpha_{\mathrm{s}}\right)}
\end{gathered}
$$

where $C_{\mathrm{l}, \mathrm{s}}$ and $C_{\mathrm{d}, \mathrm{s}}$ are the lift and drag coefficients at the stall point of angle of attack $\left(\alpha_{\mathrm{s}}\right) . C_{\mathrm{d}, \max }$ depends on the aspect ratio (AR), as shown in Equation (14):

$$
C_{\mathrm{d}, \max }=\left\{\begin{array}{c}
1.11+0.018 \mathrm{AR}, \mathrm{AR} \leq 50 \\
3.01, \mathrm{AR}>50
\end{array}\right.
$$


The VC stall model is used for the HAWT blade with variable-speed operation at low rotational speeds under steady-state conditions.

In addition, the stall delay model is dedicated to solving the rotating blade in the BEM theory [8]:

$$
\begin{gathered}
C_{\mathrm{l}, 3 \mathrm{D}}=C_{\mathrm{l}}+3\left(\frac{c}{r}\right)^{2} \Delta C_{\mathrm{l}} \\
C_{\mathrm{d}, 3 \mathrm{D}}=C_{\mathrm{d}}+3\left(\frac{c}{r}\right)^{2} \Delta C_{\mathrm{d}}
\end{gathered}
$$

where $\Delta C_{1}$ and $\Delta C_{\mathrm{d}}$ are the difference between the lift and drag coefficients obtained when the flow has no separation.

\section{The AFPM Generator Test Platform}

In this study, a ready-made AFPM generator with a coreless stator, rated at 400 Watts at $800 \mathrm{rpm}$, was used to provide the performance curves for the purpose of designing the turbine blade. The performance curves were measured using the experimental platform. A simple stator assembly, reduction of rotor surface loss, magnetic saturation and the elimination of the cogging torque are the advantages of the AFPM generator. The cogging torque elimination, which decreases the starting and cut-in speeds, has been widely used for designing the turbine blade. The generator includes a slotless toroidal-stator located between two permanent magnet (PM) rotor discs made of mild steel. The PM rotor discs have surface-mounted PMs with horseshoe shape to produce an axial magnetic field in the machine air gaps. The high-energy neodymium-iron-boron (NdFeB) PMs with a thickness of $0.005 \mathrm{~m}$ are used to enhance the excitation of the high flux density. For the AFPM generator, the outer diameter of the rotor is $0.15 \mathrm{~m}$ due to the restriction of the PM numbers, which requires $12 \mathrm{PMs}$ for one disc and $0.008 \mathrm{~m}$ for the rotor inner diameter. Nine coils with thickness of $0.011 \mathrm{~m}$ are connected in series. The outer and inner diameters of the stator are $0.15 \mathrm{~m}$ and $0.105 \mathrm{~m}$, respectively. The stator is comprised of toroidal windings with a trapezoidal shape which carried a three-phase winding, as shown in Figure 3. In addition, the stator has 114 turns per phase with a coil diameter of $0.00085 \mathrm{~m}$. All the coils are arranged to form a mold and fixed by epoxy, which has the temperature rating ranging from $100{ }^{\circ} \mathrm{C}$ to $180^{\circ} \mathrm{C}$. Some parameters such as the size of air gap, flux of air gap and magnetic field, which have no influence on testing the AFPM generator, are not presented in this study.

Figure 3. The stator and rotor of the AFPM generator.

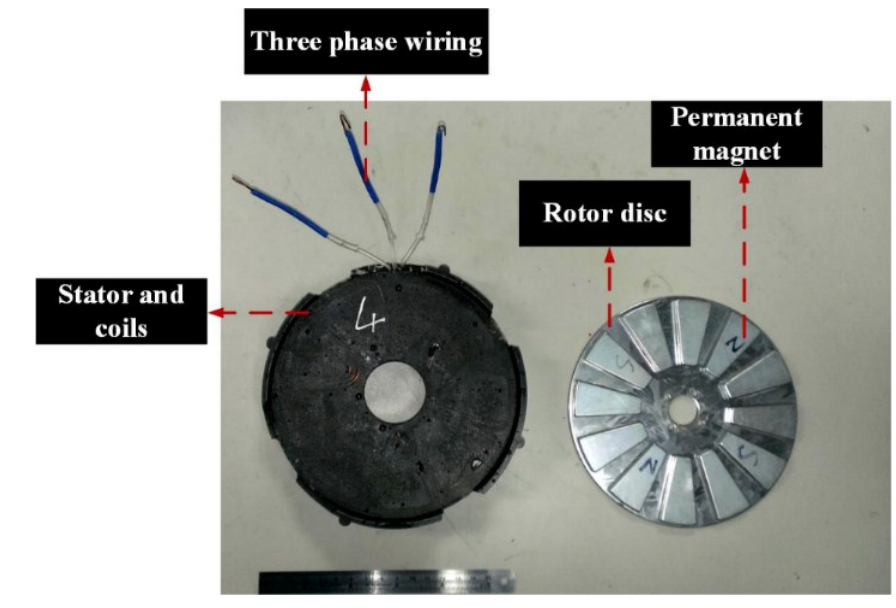


Figure 4 shows the experimental platform for measuring the performance of the AFPM generator. The $20 \mathrm{~N}-\mathrm{m}$ torque transducer (900113557, Burster, Gernsbach, Germany) was installed between the server motor and the tested generator for measuring the torque values of the generator when the server motor is driving the shaft adjusted by the variable-frequency drive.

The three-phase bridge rectification is used to convert the alternating current (AC) to direct current (DC). The high current DC electronic load module (PRODIGIT 33627F, Prodigit Electronics Co., Ltd., Taipei, Taiwan) is used to simulate the different loads of the circuit.

When the circuit loads were changed by the DC electronic load module, the rotational speeds of the generator were changed simultaneously. All data including rotational speeds, generator torques, resistances, voltages, and currents were collected by National Instrument (NI) LABVIEW.

Figure 4. The generator performance test platform.

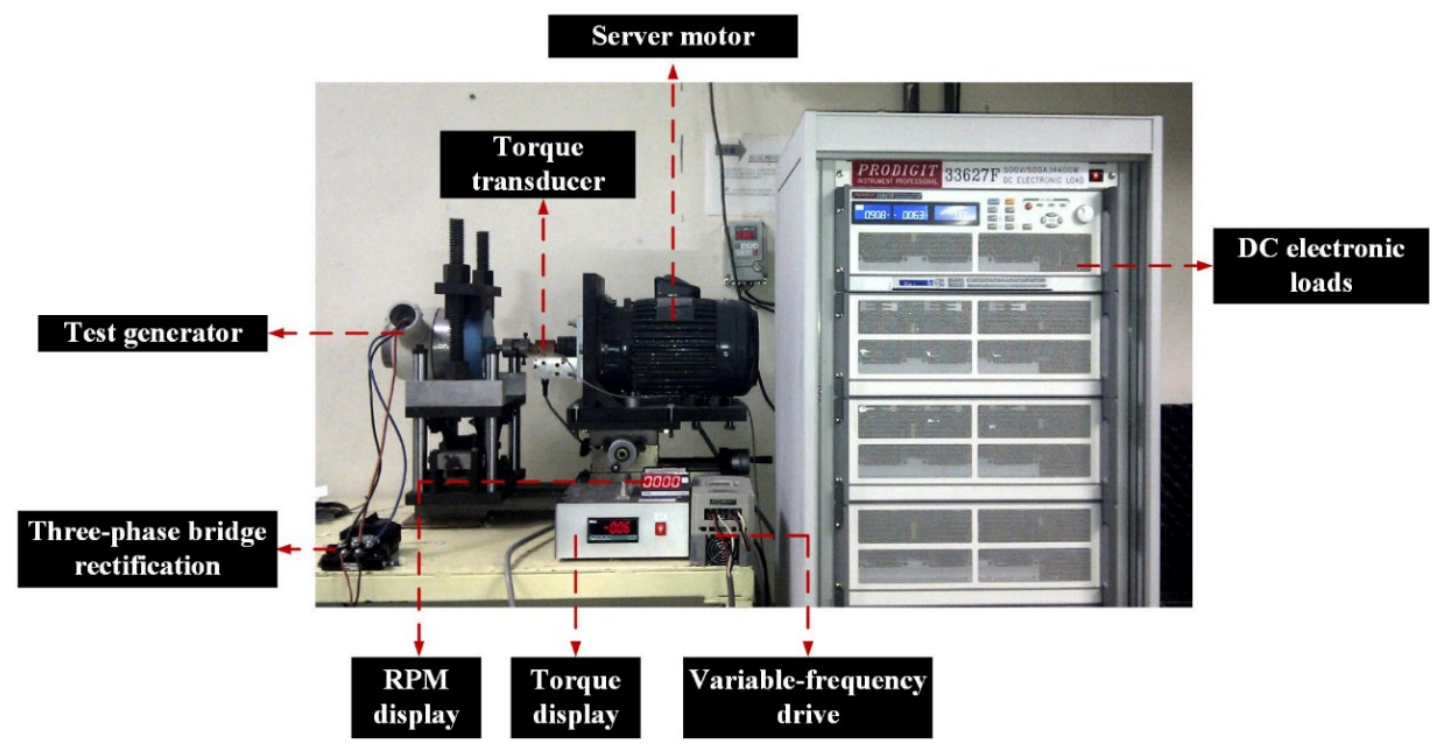

\section{Design of Turbine Blade}

\subsection{Performance of AFPM Generator}

Figure $5 \mathrm{a}-\mathrm{c}$ show the performance results obtained from the AFPM generator with various loads in the generator test platform. Figure 5a displays the AFPM generator torque $\left(T_{g}\right)$ as it varies with the rotational speed between the loads of $1.0 \Omega$ and $15 \Omega$. Obviously, the measured torques are almost linear with the rotational speeds at different loads. The maximum rotational speed is close to $1800 \mathrm{rpm}$ between the loads of $4.0 \Omega$ and $15 \Omega$ and the maximum torque is $7.9 \mathrm{~N}-\mathrm{m}$ at the load of $1.0 \Omega$ with a rotational speed of $1342 \mathrm{rpm}$. Similarly, the maximum generator power of $598 \mathrm{~W}$ is obtained at the load of $1.0 \Omega$ and the rotational speed of $1342 \mathrm{rpm}$, as shown in Figure 5b. In Figure 5c, the efficiency distributions show little changes after the rotational speed of $600 \mathrm{rpm}$ for each of the loads. It is evident that efficiencies at the loads of $1.0 \Omega, 1.4 \Omega$ and $2.0 \Omega$ are below $70 \%$. The average of efficiencies between $3 \Omega$ and $15 \Omega$ is over $70 \%$ after $700 \mathrm{rpm}$ except the load of $15 \Omega(\sim 66 \%)$. Not only can the values of efficiency provide important information for the electronic control rules, but also give the assumptions for developing the simulation code. Moreover, by varying the range of rotor speed, it is proven that the AFPM generator is suitable for designing small scale HAWT blades [30]. 
For designing a turbine blade, it is necessary to determine an appropriate correlation between the rotational speeds and the generator torques/powers. High rotational speeds result in different performance predictions, which exceed the operational range of the generator. The zone covered with rotational speeds between $700 \mathrm{rpm}$ and $1000 \mathrm{rpm}$, the generator torques between $2 \mathrm{~N}-\mathrm{m}$ and $5 \mathrm{~N}-\mathrm{m}$ and the generator powers between $200 \mathrm{~W}$ and $410 \mathrm{~W}$ are selected in this study for designing the turbine blade based on the performance of the AFPM generator. The reliability of this blade design zone is verified in the following sections.

Figure 5. Results of AFPM generator at different rotational speeds for (a) torque; (b) power; and (c) efficiency.

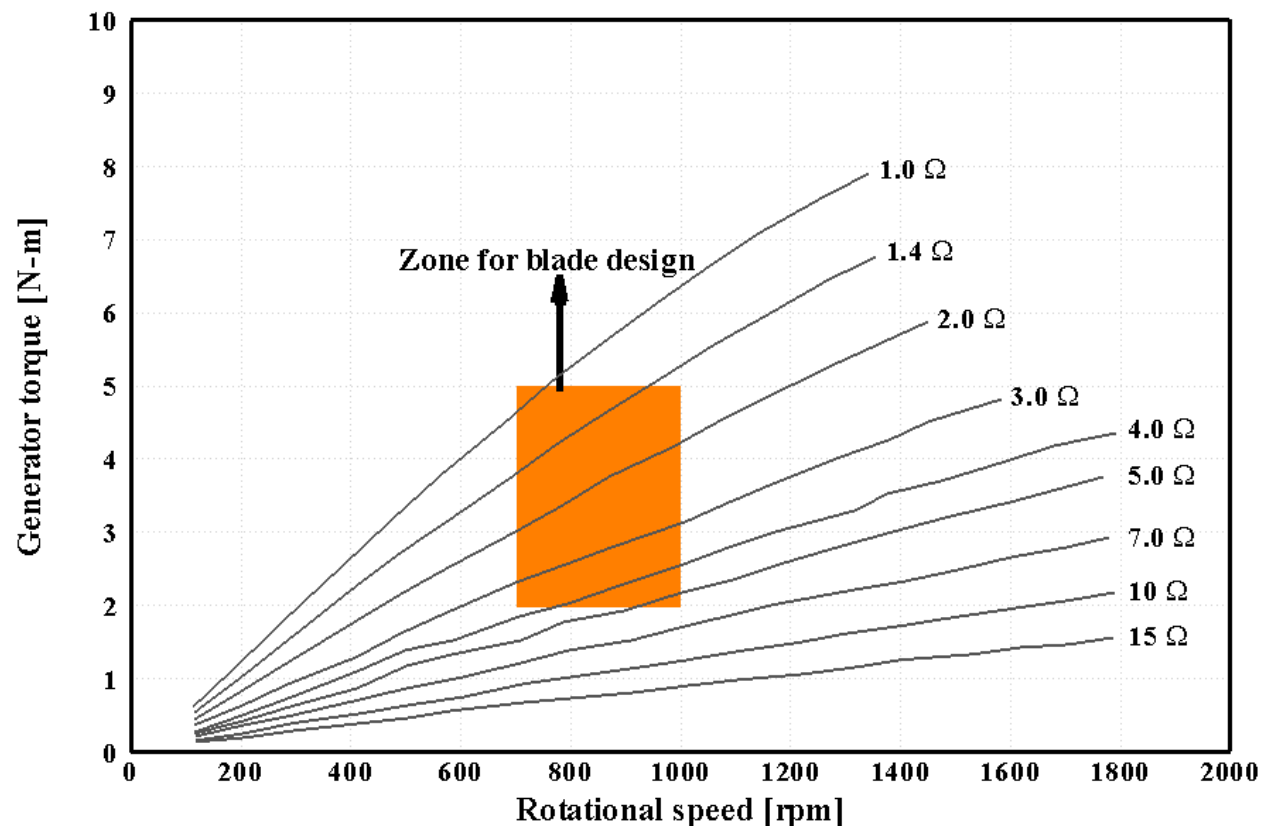

(a)



(b) 
Figure 5. Cont.

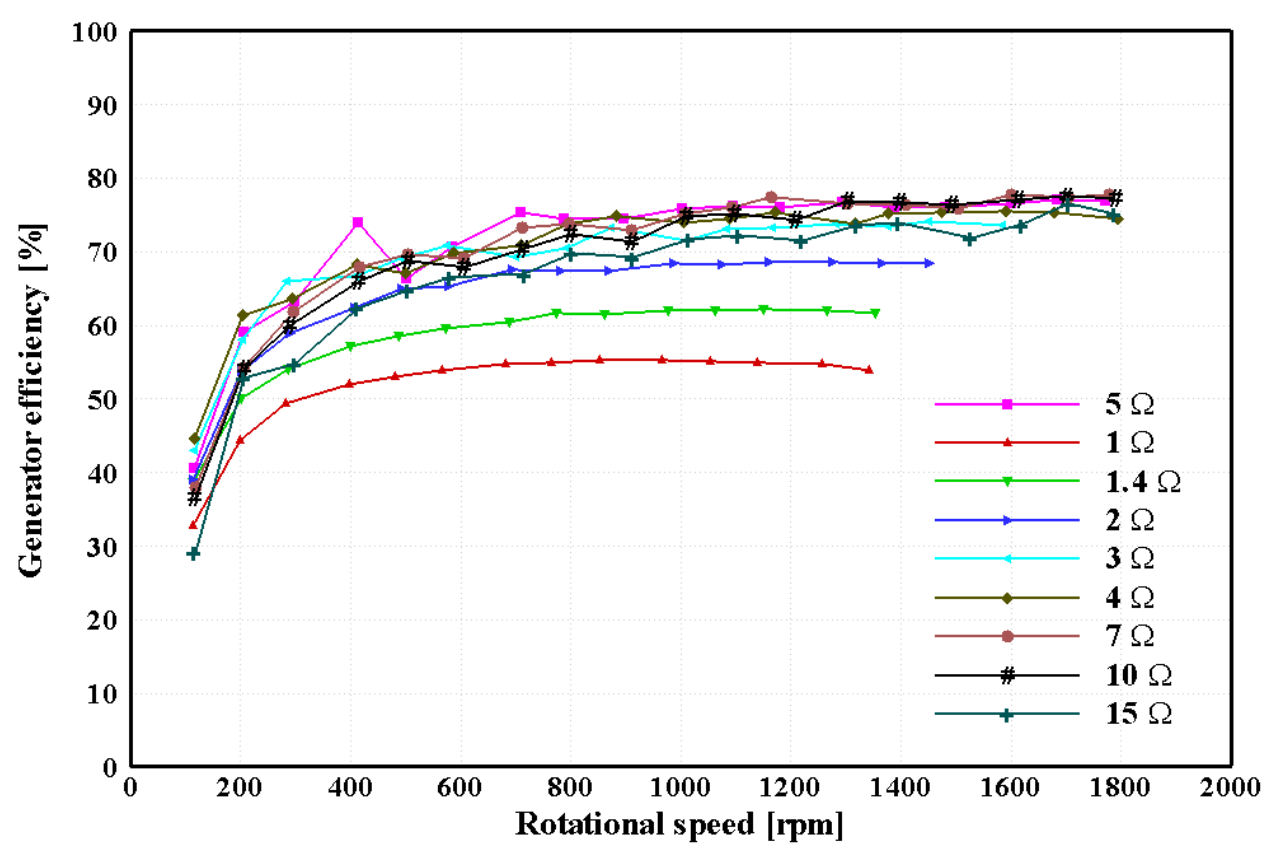

(c)

\subsection{Geometry for Turbine Blade}

The radius of blade is calculated based on the prediction of rated power, rated wind speed and total system efficiency:

$$
R=\sqrt{\frac{2 P_{\text {rated }}}{\rho \pi V_{\text {rated }}^{3} \eta_{\text {total }}}}
$$

where $P_{\text {rated }}$ is the rated power, output from the blade, $V_{\text {rated }}$ is the rated wind speed, usually assumed to be between $10 \mathrm{~m} / \mathrm{s}$ and $12 \mathrm{~m} / \mathrm{s}$ [5,6,11], $\rho$ is the air density, and $\eta_{\text {total }}$ is the total system efficiency, suggested to be $25 \%$ to $35 \%$ [11]. The system integration between the turbine blade and the generator is not considered in Equation (17).

The rated power and the total system efficiency in Equation (17) have strong correlations with the electric generator. The rated power is the power output at the rated running conditions extracted from the turbine blade. The generator provides the same power outputs as the turbine blade at these conditions; therefore, the rated power in Equation (17) is assumed to be the generator power. The total system efficiency is the product of the power coefficient $(\mathrm{Cp})$, the mechanical efficiency $\left(\eta_{m}\right)$, and the electrical efficiency $\left(\eta_{g}\right)$. The power coefficient represents the fraction of the power extracted from the turbine blade. In the simulation model, $\mathrm{Cp}$ is assumed to be between the values of 0.38 and 0.45 in Equation (17). Previously, Hirahara et al. [11] obtained experimentally the maximum power coefficient of 0.40 and 0.36 in the rated running conditions using the HAWT blade with a radius of $0.25 \mathrm{~m}$. Hsiao et al. [5] obtained a maximum power coefficient of the HAWT blade to be 0.428 at the tip speed ratio of 4.92 using the BEM theory and wind tunnel experiments. The power coefficient in this study was assumed to be 0.4 based on the studies mentioned above. The mechanical efficiency generated by the heat, friction, electric, etc. is obtained from the wind tunnel experiments. It is more 
than $70 \%$ when the rotational speed is between $700 \mathrm{rpm}$ and $1000 \mathrm{rpm}$ at the loads of $3 \Omega$ to $10 \Omega$, as shown in Figure 5c. Therefore, $\eta_{m}$ is assumed to be 0.73 . The electrical efficiency is yielded by the electronic control system, which is not discussed in this study. Therefore, Equation (17) can be modified as:

$$
R=\sqrt{\frac{2 P_{g}}{\rho \pi V_{\text {rated }}^{3} \eta_{m \mathrm{c}_{\mathrm{p}}}}}=\sqrt{\frac{2 T_{g} \omega}{\rho \pi V_{\text {rated }}^{3} \eta_{m \mathrm{c}_{\mathrm{p}}}}}
$$

where $T_{g}$ is the generator torque measured by the generator performance test platform (Figure 4); $\eta_{m}$ is the generator efficiency obtained from experiment; and $\omega$ is the rotational speed of the generator. The power of the generator is the product of generator torque and rotational speed. The generator torque varies with different rotational speeds.

Figure 6 shows the predicted results of the radius of blade as it varies with the generator power at wind speeds of 10, 11 and $12 \mathrm{~m} / \mathrm{s}$. The radius of the blade was calculated based on Equation (18) with the assumed $\mathrm{Cp}$ value of 0.40 . It is observed that the radius of blade is designed between $0.43 \mathrm{~m}$ and $0.83 \mathrm{~m}$ when the yield of generator power output is between $200 \mathrm{~W}$ and $420 \mathrm{~W}$. In Figure 7, the distribution of radius of blade is plotted with varying power coefficients using Equation (18). For example, the radius of the designed blade is calculated as 0.65 mas the $P_{g}, \rho, V, \mathrm{Cp}$ and $\eta_{m}$ are respectively assumed to be $400 \mathrm{~W}, 1.225 \mathrm{~kg} / \mathrm{m}^{3}, 12 \mathrm{~m} / \mathrm{s}, 0.40$ and 0.73 .

For designing the turbine blade, it is necessary to obtain the rotational speeds. The parameters for determining the rotational speed for a turbine blade include the wind speed $(V)$ and the radius of blade $(R)$, defined as a non-dimensional parameter called tip speed ratio (TSR):

$$
\operatorname{TSR}=\frac{R \omega}{V}
$$

Figure 6. Distributions of the blade radius with the generator power at the wind speed of $10 \mathrm{~m} / \mathrm{s}, 11 \mathrm{~m} / \mathrm{s}$ and $12 \mathrm{~m} / \mathrm{s}$.

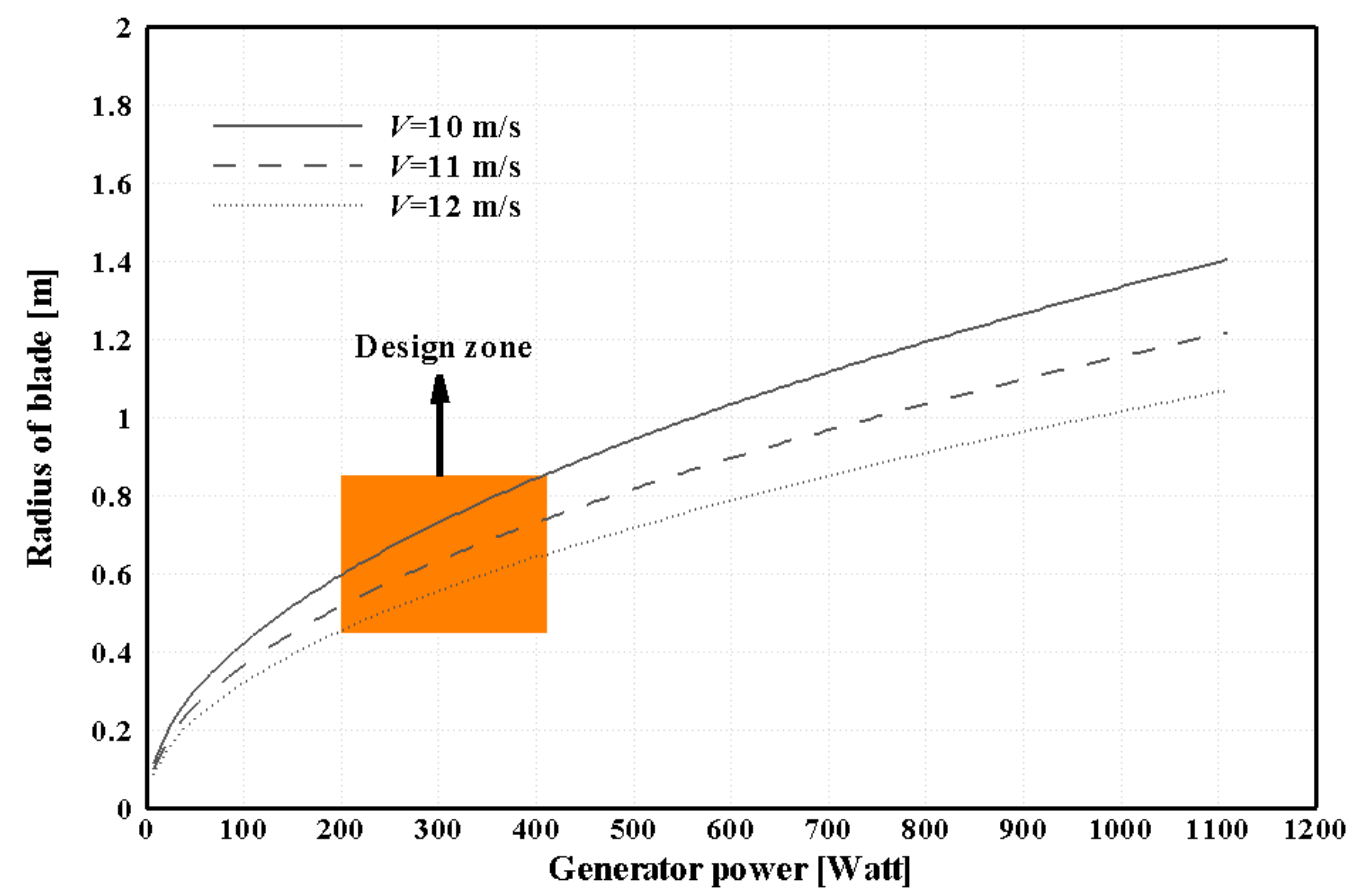


Figure 7. Distributions of $r$ the blade radius with the generator power at the power coefficient (Cp) of $0.40,0.45,0.50$.

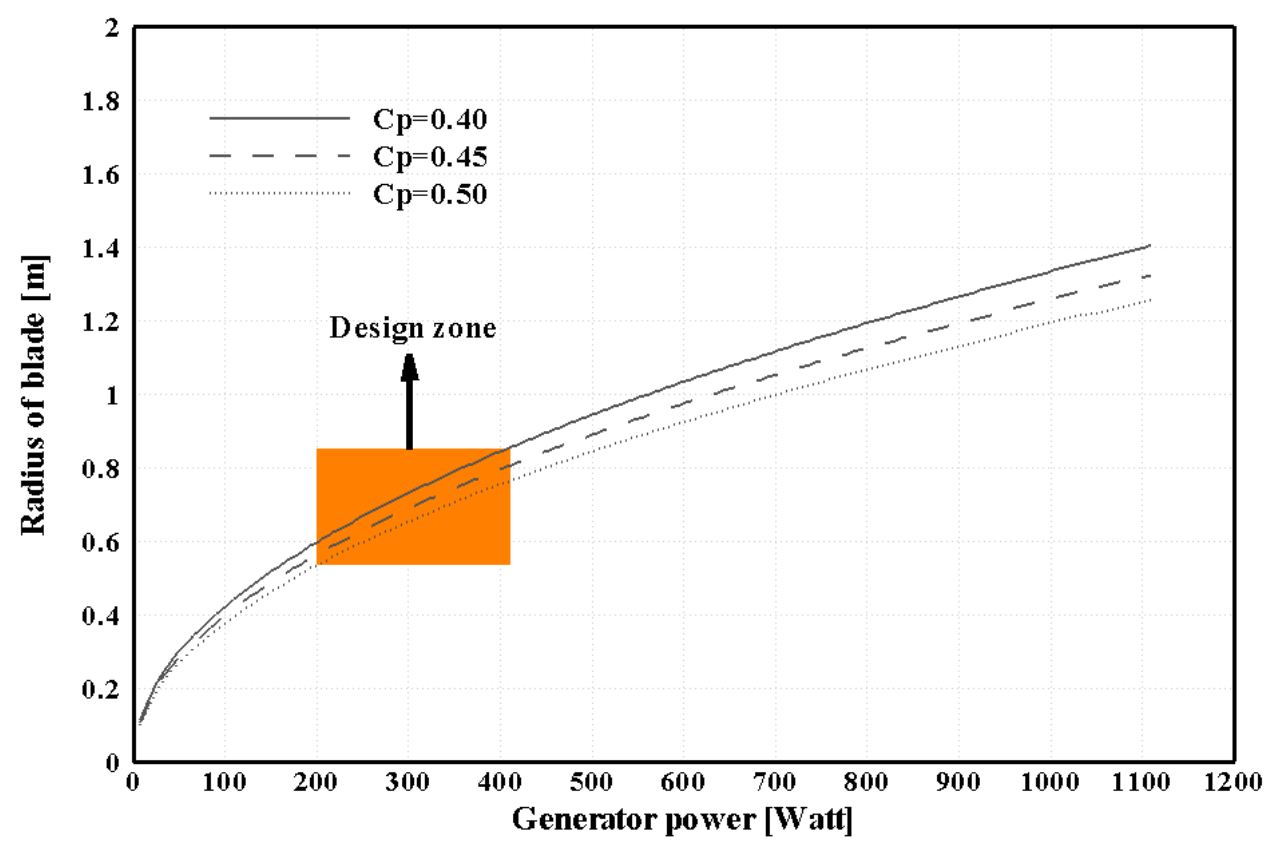

For selecting the values of TSR, it is suggested to choose 4-10 for the application of wind turbine systems [27]. The radius of the blade, based on Equation (18), is therefore calculated to be $0.65 \mathrm{~m}$. Figure 8 indicates the 3D surface plot between the tip speed ratios, the wind speeds, and the rotational speeds as the radius of blade is $0.65 \mathrm{~m}$. It is observed that the rotational speed increases with the increasing wind speed and tip speed ratio. As the rotational speed operates at $700 \mathrm{rpm}$ to $1000 \mathrm{rpm}$, the tip speed ratio and the wind speed are chosen between 4-7 and 8-12 m/s, respectively.

Figure 8. Relationship between the tip speed ratios, wind speeds, and rotational speeds at the radius of blade of $0.65 \mathrm{~m}$.

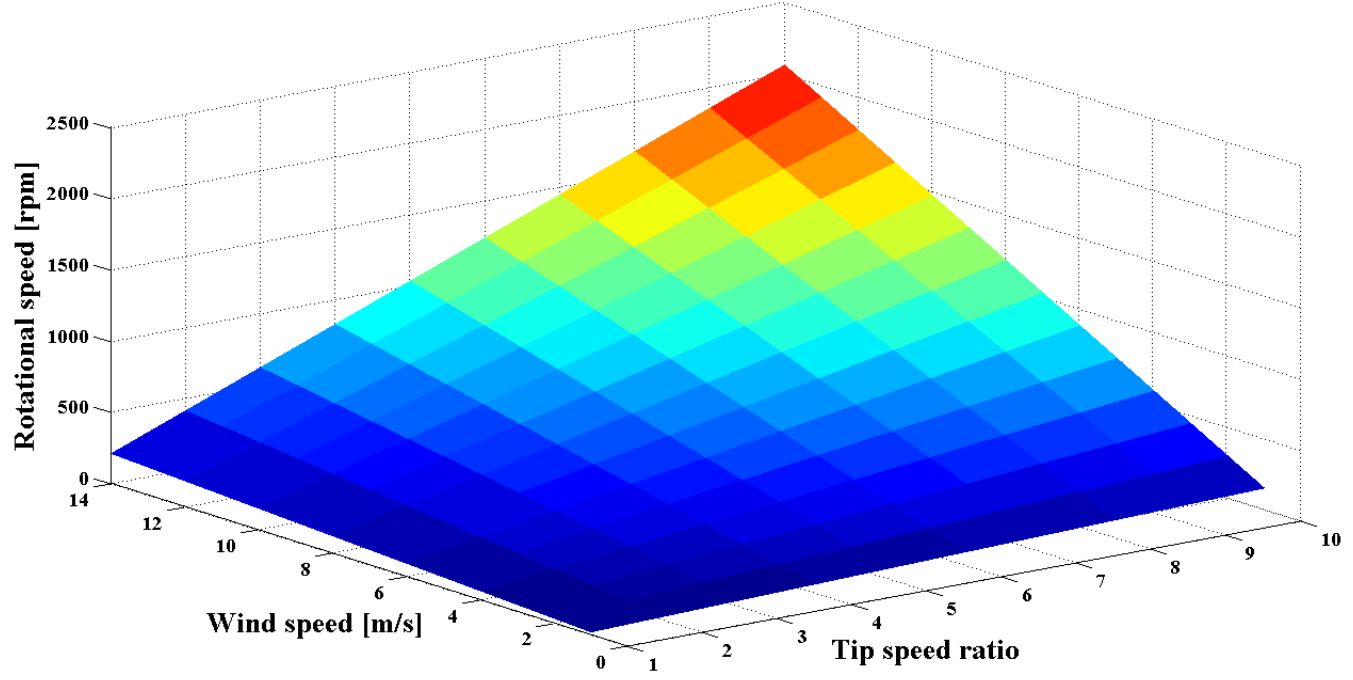

From the concept of BEM theory, the design for increasing the aerodynamic performance of the 3-D turbine blade is based upon the 2-D airfoil designs. For this reason, to design the shape of the turbine blade, the 2-D airfoil needs to be selected before laying out the pitch angle and chord length in 
each section. The chord length is determined through the lift coefficient for an airfoil (Equation (1)) if the pitch angle in each of the sections is calculated from the designed angle of attack (Equation (2)). In this study, the SD8000 airfoil was used to lay out the geometries of the turbine blade. The designed angle of attack of $5^{\circ}$ with the lift coefficient of 0.734 was chosen, and here the designed angle of attack is based on the maximum lift-to-drag ratio of 57 with the Reynolds number of $2 \times 10^{5}$ [28]. In addition, $\mathrm{Re}=1 \times 10^{5}$ and $3 \times 10^{5}$ are used in the simulation code. Figure 9 shows the distributions of chord length in each section with the designed tip speed ratio between 1 and 10 .

Figure 9. Relationship between the tip speed ratio, the local radius, and the chord length at the radius of blade of $0.65 \mathrm{~m}$.

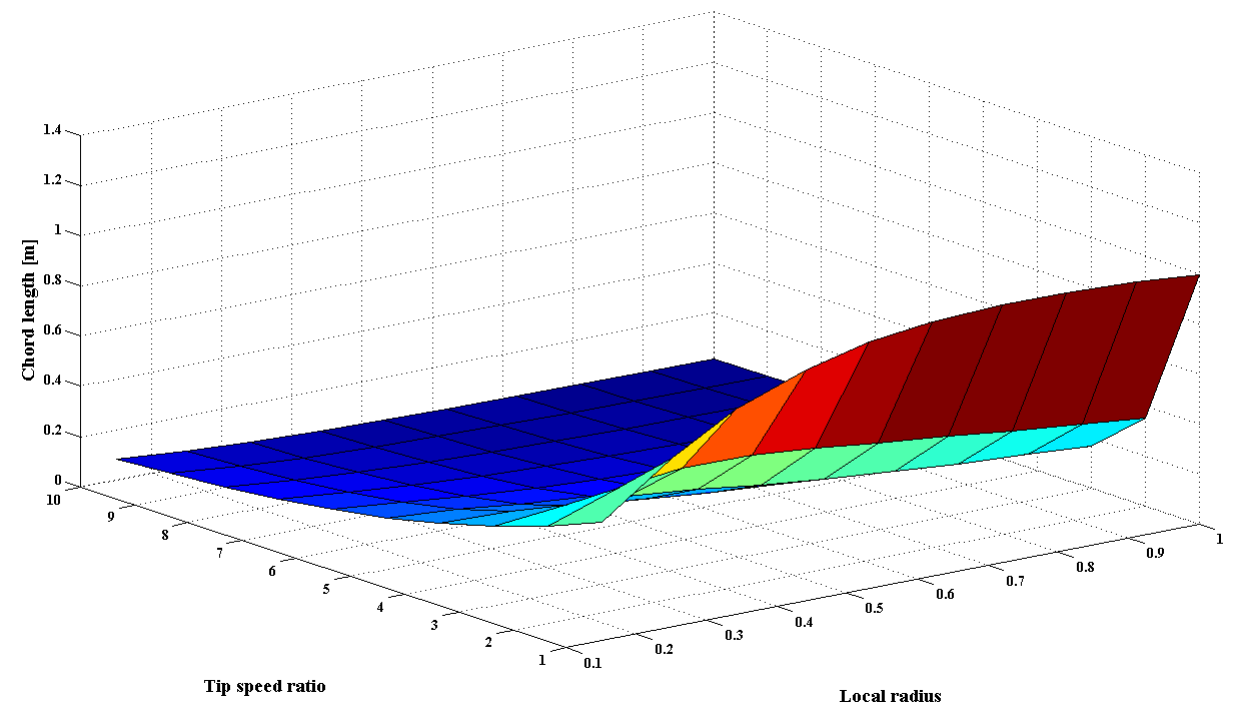

It is obvious that the chord length distributions decrease with the increasing tip speed ratio. It is suggested that the turbine blade requires more area to convert the wind energy to the mechanical power at the lower rotational speeds (or the lower tip speed ratios). Figure 10 shows the relationship between the local radius, the tip speed ratio, and the pitch angle at the blade radius of $0.65 \mathrm{~m}$. It is clearly seen that the pitch angle is more than $30^{\circ}$ in the blade root region when the designed tip speed ratios are between 1 and 4 . The empirical pitch angle of the blade surface is no more than $30^{\circ}$ due to the complexity of manufacturing in the blade root region using the 3-axis Computer Numerical Control (CNC) machine with acrylonitrile butadiene styrene (ABS) materials. Another issue is the interaction between the root of blade and the hub. If the angles are too large at the blade root region, it may strike the hub when the blade is rotating. As mentioned above, the designed tip speed ratio is selected to be 5, leading the rotational speed to be $881.5 \mathrm{rpm}$ according to the assumptions of blade radius of $0.65 \mathrm{~m}$ and wind speed of $12 \mathrm{~m} / \mathrm{s}$ (Equation (18)). All parameters for the turbine blade design in this study are listed in Table 1. Figure 11 shows the layout of the designed turbine blade from Equations (1) and (2). The maximum chord length and the pitch angle located on the blade root region are $0.206 \mathrm{~m}$ and $30^{\circ}$ respectively. 
Figure 10. Relationship between the tip speed ratio, the local radius, and the pitch angle at the radius of blade of $0.65 \mathrm{~m}$.

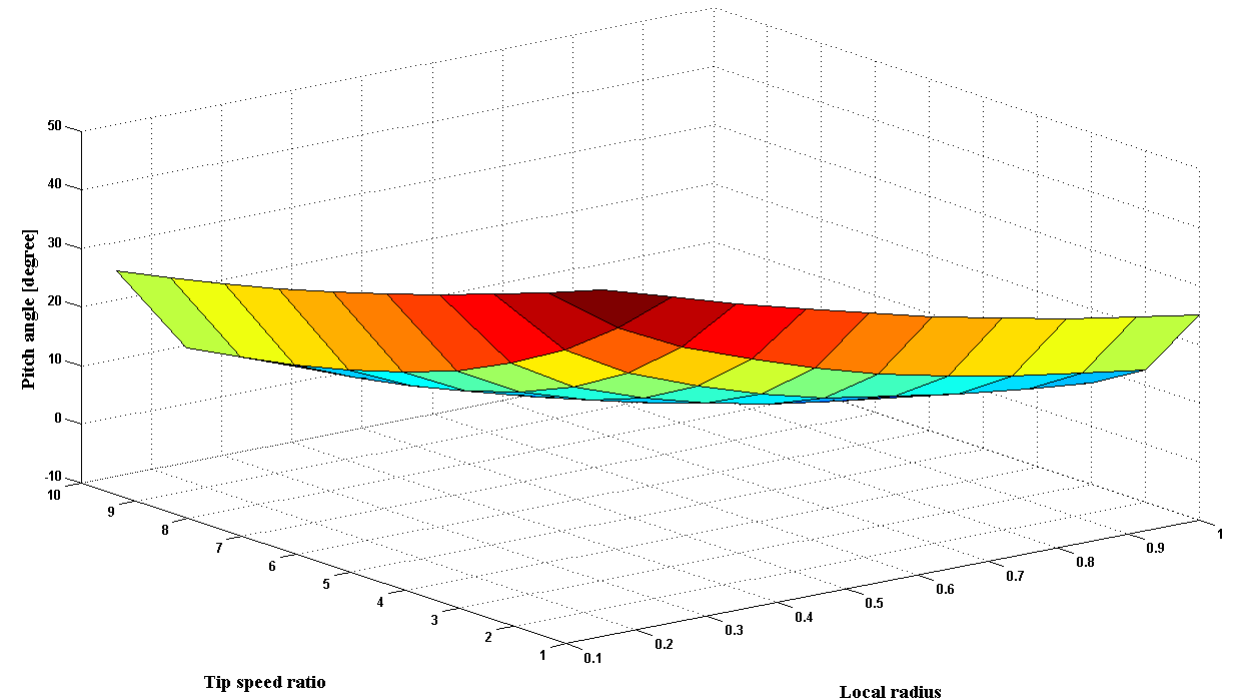

Table 1. The blade design parameters.

\begin{tabular}{cc}
\hline Characteristics & Values \\
\hline Rated power $(\mathrm{W})$ & 400 \\
Rated wind speed $(\mathrm{m} / \mathrm{s})$ & 12 \\
Designed tip speed ratio & 5 \\
Number of blades & 3 \\
Designed angle of attack $\left(^{\circ}\right)$ & 5 \\
Airfoil type & SD8000 \\
\hline
\end{tabular}

Figure 11. Layout of the chord length and pitch angle for the designed turbine blade.

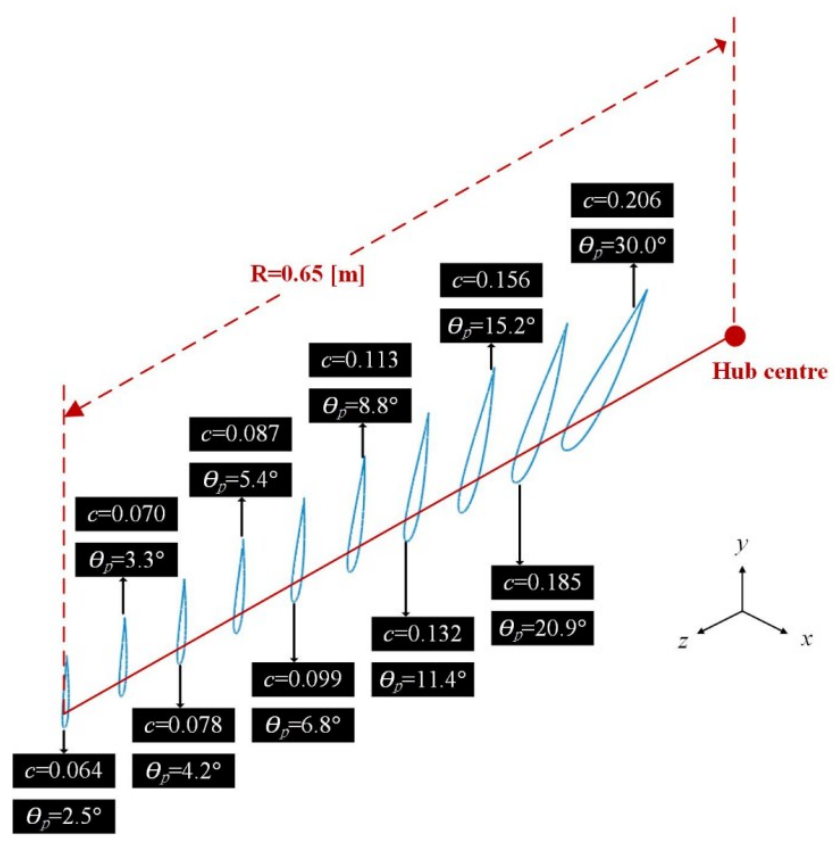




\section{Wind Tunnel Testing}

To compare with the simulation results, the design turbine blade was tested in a full-scale wind tunnel, as shown in Figure 12. The wind tunnel is a type of closed circuit with two test sections. The test section is $36.5 \mathrm{~m}$ (length) and the area of cross section is $4.0 \mathrm{~m}$ wide $\times 3.6 \mathrm{~m}$ high. The maximum wind speed in the test section is $36 \mathrm{~m} / \mathrm{s}$, and has been verified through many parameters including structure vibration, temperature, stability, flow uniformity, turbulence intensity, flow angularity, and boundary layer thickness. The mean flow uniformity is about $0.37 \%$ and the turbulence intensity is less than $0.25 \%$ as well as the boundary layer thickness is about $60 \mathrm{~mm}$ at the inlet cross section. The average flow angularity of the pitch and yaw angles are, respectively, about $\pm 0.415^{\circ}$ and $\pm 0.97^{\circ}$ below the wind speed of $20 \mathrm{~m} / \mathrm{s}$. A pitot-static tube was installed to measure the free stream velocity in the test section because it is stable, accurate and convenient to calibrate. The variable reluctance pressure transducer (Model CD23, Validyne Engineering Co., Northridge, CA, USA) is connected to the pitot-static tube and converts the pressure difference between the total pressure and the static pressure into electric voltage. The small analog signal was then amplified and converted using an analog/digital converter. The pressure transducer was calibrated by a micro manometer and verified before the experiments. The flow speed in the test section was calculated based on the incompressible steady Bernoulli's equation.

To understand the influence of the blockage, it is necessary to consider the area ratio:

$$
\mathrm{Ab} / \mathrm{A}_{\mathrm{w}}
$$

where $A_{b}$ is the turbine blade swept area and $A_{w}$ is the cross section of the wind tunnel test section. Based on the literature [31], to avoid any interference from the wind tunnel wall when measuring the power coefficient and any blockage effect correction, the maximum area ratio has to be below $10 \%$ [32]. For example, the NREL wind turbine, with the turbine blade radius of $5 \mathrm{~m}$, has the area ratio of $8.8 \%$ when it is tested in the full-scale wind tunnel [33]. In this case, the areas of the wind tunnel test section and turbine blade swept region are $14.4 \mathrm{~m}^{2}$ and $1.3273 \mathrm{~m}^{2}$ respectively, and therefore the area ratio is below $10 \%(9.2 \%)$.

A high current DC electronic load module was used to manipulate different loads of the circuit. When the circuit load changes, the rotational speed of the blade changes simultaneously. In addition, measuring the signal of the rotational speed for the rotor blade is necessary. The proximity switch, consisting of a tachometer and proximity switch, is used to measure the DC signal of rotational speed (rpm) for the turbine blade. The simplest type of rectifier, named the diode bridge circuit, is used to convert the AC to fluctuating DC.

A $5 \mathrm{~N}-\mathrm{m}$ torque transducer (110125, Burster, Gernsbach, Germany) mounted on the main shaft between the turbine blade and the generator was also used to measure the mechanical torque, leading to the calculation for the power coefficient (Figure 12) [5].

The voltage outputs from these sensors were acquired by the AD converter (USB-6008, National Instrument Co., with the Labview software as the interface. For measuring the voltage and rotational speeds in the wind tunnel, the sampling frequency was fixed at $3 \mathrm{k}-\mathrm{Hz}$ and sampled at $6 \mathrm{k}-\mathrm{Hz}$ per point. The data acquisition period is $2 \mathrm{~s}$. 
Figure 12. The wind turbine system setup in the full-scale wind tunnel.

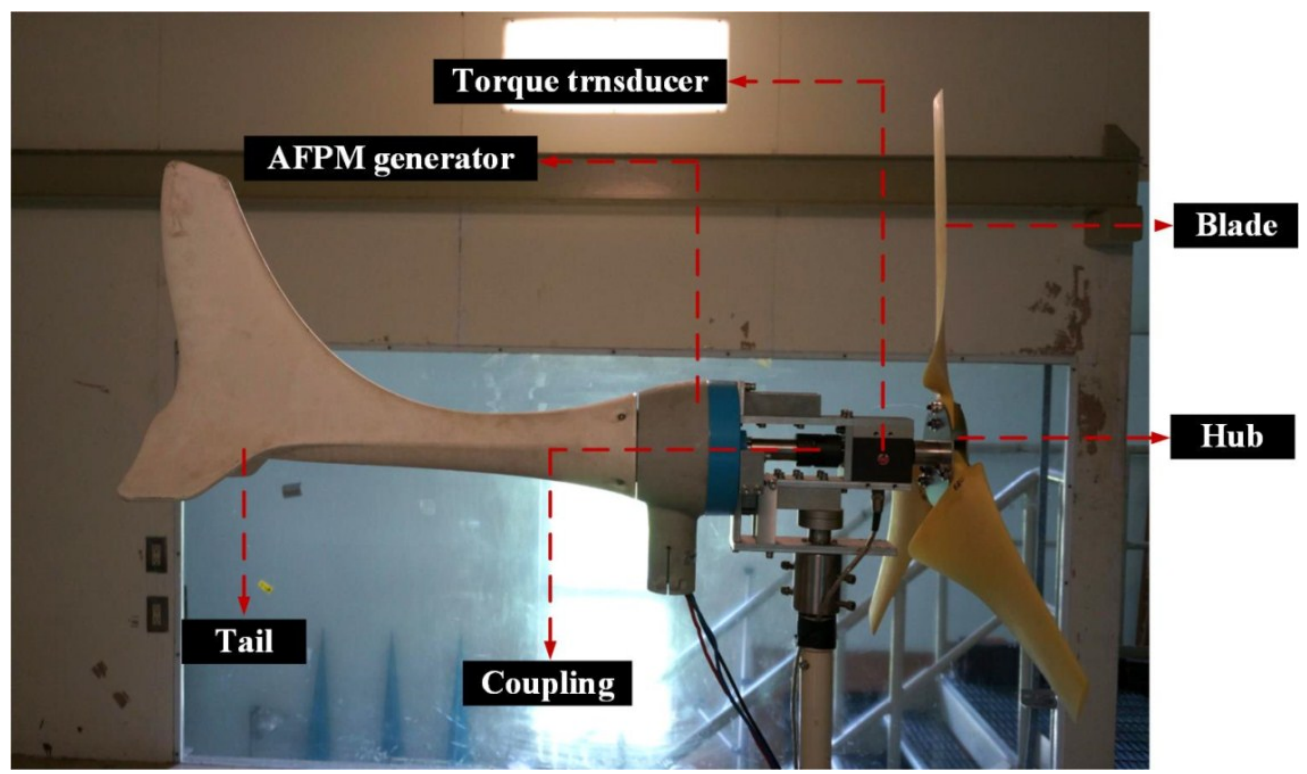

\section{Comparison of the Simulation and Experimental Results}

Figure $13 \mathrm{a}-\mathrm{d}$ show the comparisons of the experimental and simulation results for the mechanical torques and mechanical powers against the rotational speeds at wind speeds of $6,8,10$, and $12 \mathrm{~m} / \mathrm{s}$. The angles of attack for the turbine blade can be divided into three parts: (1) region A, ranging from $15^{\circ}$ to $33^{\circ}$; (2) region $\mathrm{B}$, ranging from $5^{\circ}$ to $15^{\circ}$; (3) region $\mathrm{C}$, ranging from $5^{\circ}$ to $-8^{\circ}$. It is observed that the curve of the mechanical torques behaves differently from the one for the mechanical powers. In region $\mathrm{A}$, the mechanical torques and powers increase with decreasing angles of attack. However, region A represents the stall region for the turbine blade, suggested to be a bad region for operating the wind turbine system. The maximum torque at wind speeds of $6,8,10$, and $12 \mathrm{~m} / \mathrm{s}$ occurs at the region $\mathrm{B}$ and at the rotational speeds of 350, 380, 550 and $700 \mathrm{rpm}$, respectively. Since region B is the one close to the stall region, instability of the turbine blade such as vibration was observed during the wind tunnel experiments. The maximum mechanical power for the various wind speeds occurs at the region $\mathrm{C}$ and at the rotational speeds of 550, 750, 950 and $880 \mathrm{rpm}$, respectively. It is noted that at the wind speed of $12 \mathrm{~m} / \mathrm{s}$, the maximum value of mechanical power is $530 \mathrm{~W}, 26 \%$ more than the rated power $(400 \mathrm{~W})$. In addition, this value was observed close to the designed angle of attack $\left(\alpha=5^{\circ}\right)$, which is the point that the maximum ratio of lift to drag coefficient at $\mathrm{Re}=1 \times 10^{5}$ presents, that is, where the highest power output occurs. Therefore, controlling the mechanical powers at various wind speeds is significant for the application of electric control system, such as the maximum power point tracking (MPPT) method. At the wind speed of $12 \mathrm{~m} / \mathrm{s}$, the experimental data were constrained to the rotational speed of $1300 \mathrm{rpm}$ due to the limitations of the blade structure. However, the mechanical torques and powers at this region can be obtained from the prediction. Moreover, the simulation results have good agreement with the experimental results except the region between the angles of attack of $7^{\circ}$ and $17^{\circ}$. The deviation of the experimental and simulation data in this region results from the complex flow field such as the separation flow phenomenon. The predictions of the mechanical torque and power at the best operating region $\left(\alpha=5^{\circ}\right.$ to $\left.-8^{\circ}\right)$ provides significant information for designing the wind turbine blade. 
Figure 13. The comparison of mechanical torques/powers between the experiment and simulation results at wind speed of (a) $6 \mathrm{~m} / \mathrm{s}$; (b) $8 \mathrm{~m} / \mathrm{s}$; (c) $10 \mathrm{~m} / \mathrm{s}$ and (d) $12 \mathrm{~m} / \mathrm{s}$.



(a)

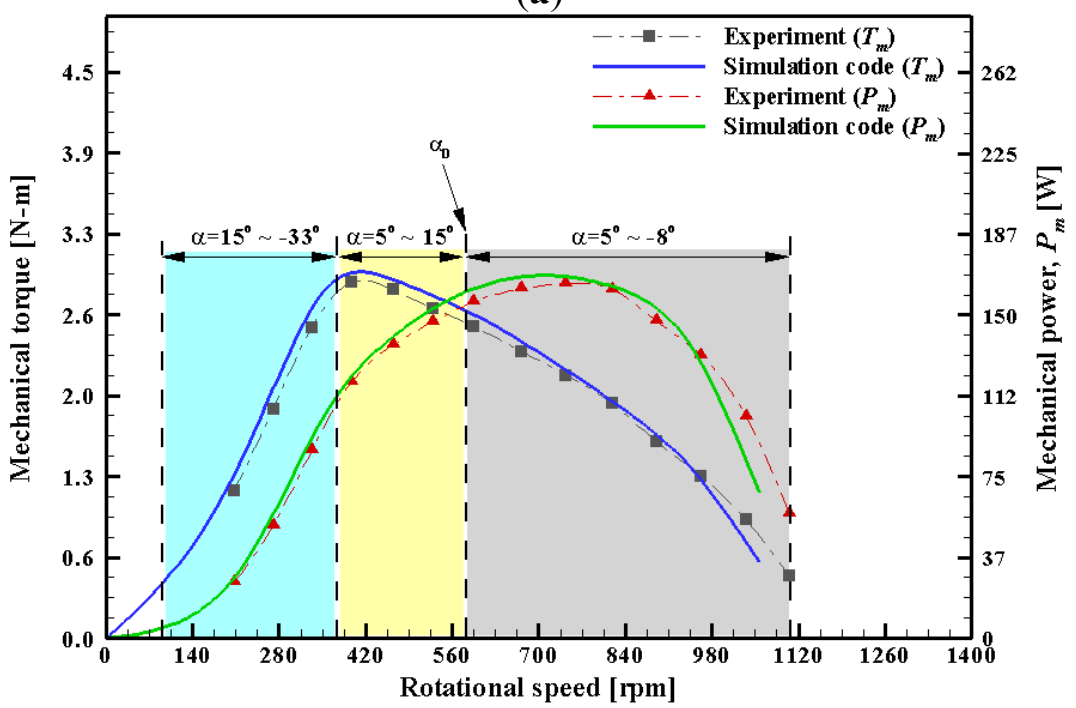

(b)

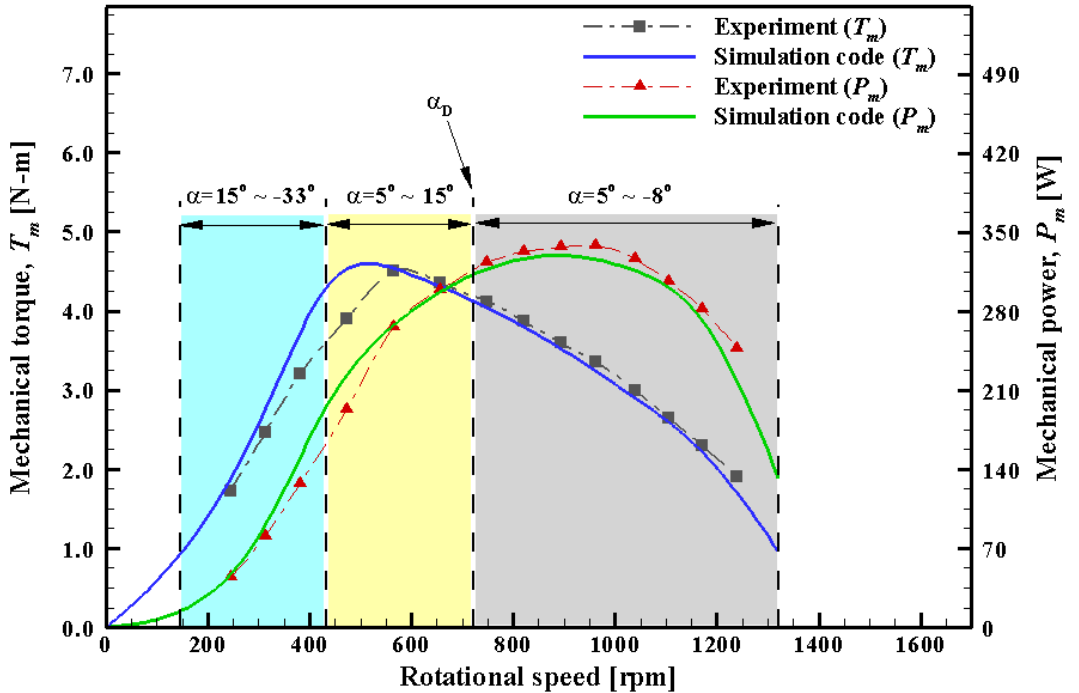

(c) 
Figure 13. Cont.

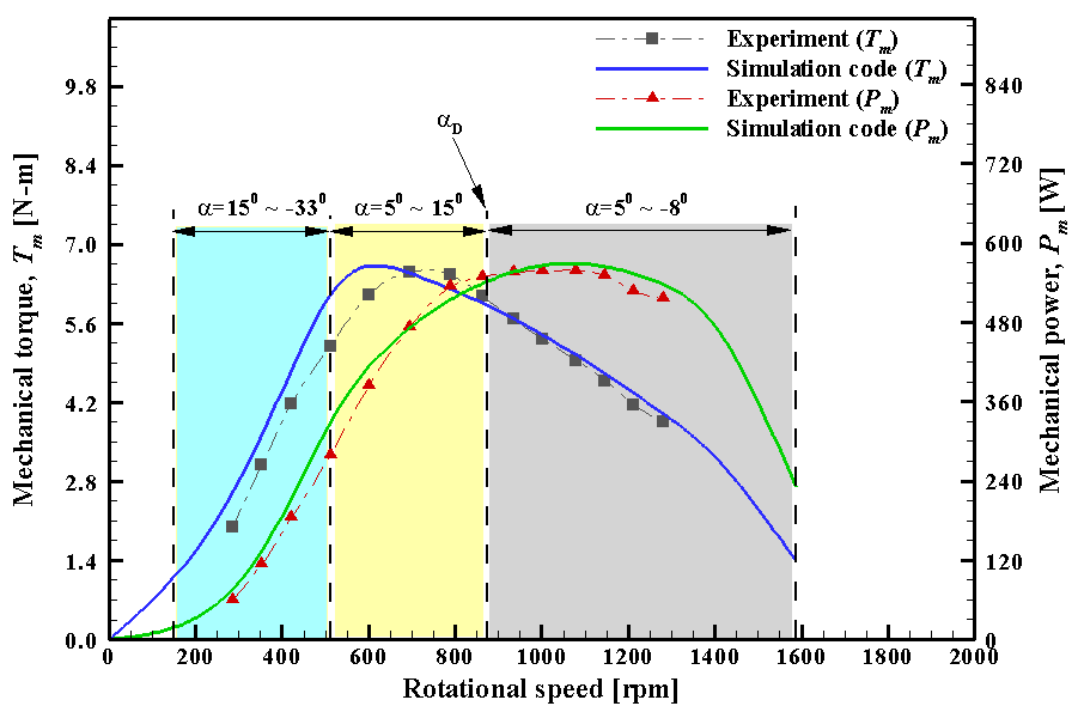

(d)

In Figure 14a,b, the distributions of the mechanical torque and power, predicted by the simulation code, have been adapted to the experimental results obtained from the tests of the AFPM generator. All curves of the mechanical torque and power overlap the generator torques and powers. The matching points represent the corresponding mechanical torques and powers to the generator torques and powers at certain operating conditions. For example, the mechanical torque and power at the wind speed of $10 \mathrm{~m} / \mathrm{s}$, rotational speed of $900 \mathrm{rpm}$ and generator torque of 2 omega are $4 \mathrm{~N}-\mathrm{m}$ and $380 \mathrm{~W}$, respectively. With more testing results, a look-up table for designing a wind turbine system can be demonstrated. In addition, the selected zone for designing the turbine blade falls into the area covered with the matching points. In other words, the zone is reliable for designing the turbine blade of the HAWT system.

Figure 14. Distributions of (a) torque and (b) power between the generator and mechanical results at different rotational speeds.

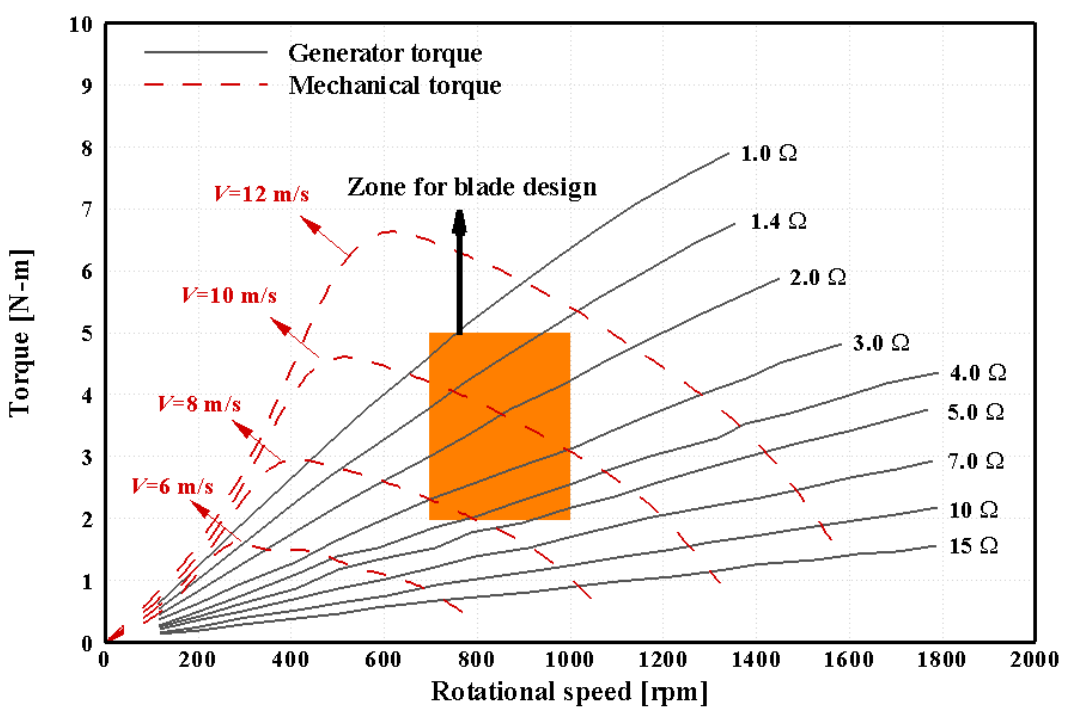

(a) 
Figure 14. Cont.

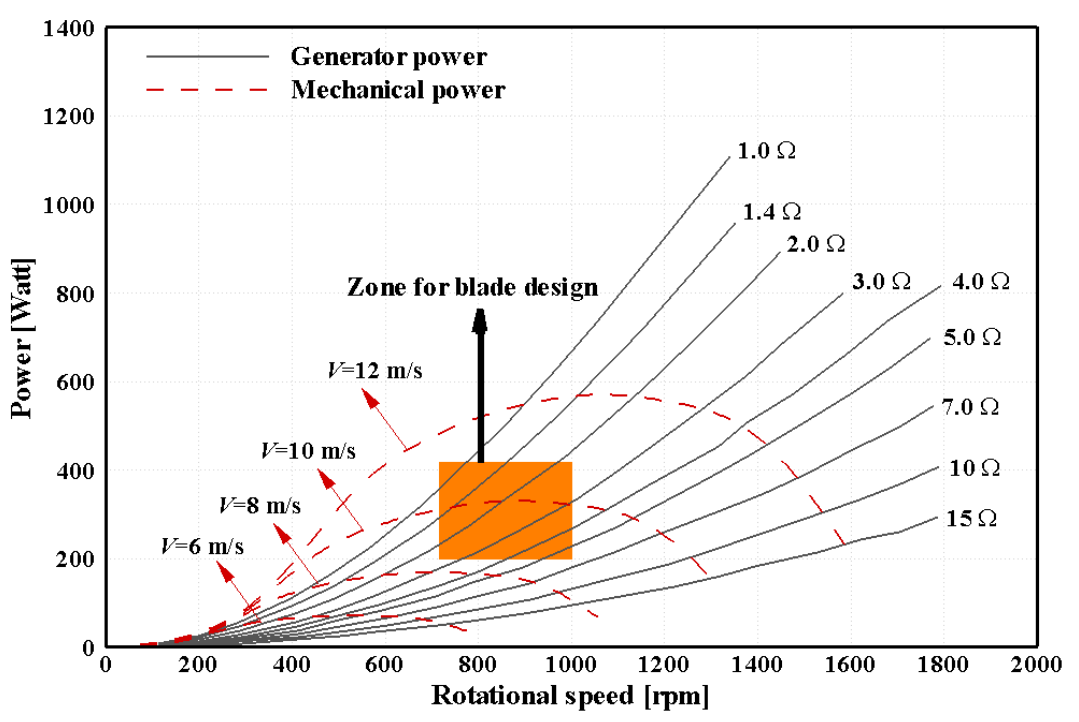

(b)

Figure 15 shows the comparison of power coefficients obtained from experiments and simulation at wind speed of $12 \mathrm{~m} / \mathrm{s}$. Based on both of the results, the maximum power coefficient is 0.40 at tip speed ratio of 5.3. The results from simulation have good agreement with the experimental data, showing that the prediction of the power coefficients via the developed simulation code is reliable.

Figure 15. Comparison of the power coefficients between experimental and simulation results at wind speed of $12 \mathrm{~m} / \mathrm{s}$.



\section{Conclusions}

System integration between the design of the wind turbine blade and the test of the generator performance has become an important issue for developing a HAWT system. The aerodynamic design of the turbine blade for a small scale HAWT system based on an AFPM generator has been carried out in this study. The performance curves of the ready-made AFPM generator were plotted based on the 
measurement at the various loads, providing significant information for designing the geometry of the turbine blade. The generator torques and powers were measured based on the loads of 1 to $10 \Omega$, ranging from 0.2 to $8 \mathrm{n}-\mathrm{m}$ and from 50 to $1150 \mathrm{Watt}$, respectively. The highest generator efficiency is $73 \%$, occurring at the load of $5 \Omega$. By applying all the parameters, the designed radius of the turbine blade is $0.65 \mathrm{~m}$. Also, the characteristics of the SD8000 airfoil is embedded into the simulation code to lay out the sectional chord length and pitch angle. In addition, the aerodynamic performance of the designed HAWT blade was tested in a wind tunnel to verify the simulation results. The experimental and simulation results of the mechanical torques and powers, which vary with the rotational speeds at four different wind speeds, demonstrate good agreement. The maximum mechanical power, which occurred close to the designed angle of attack, is a good indication for the wind turbine system integration.

\section{Acknowledgments}

This project was partially supported by the NCKU Research Center for Energy Technology and Strategy 5Y5M Grand D103-23017 under the Ministry of Education of Taiwan and the Ministry of Science and Technology through Grant NSC 102-2221-E-006-084-MY3.

\section{Author Contributions}

Each of the authors contributes on performing experiments and writing articles.

\section{Conflicts of Interest}

The authors declare no conflict of interest.

\section{References}

1. Madlener, R.; Latz, J. Economics of centralized and decentralized compressed air energy storage for enhanced grid integration of wind power. Appl. Energy 2013, 101, 299-309.

2. McKenna, R.; Hollnaicher, S.; Fichtner, W. Cost-potential curves for onshore wind energy: A high-resolution analysis for Germany. Appl. Energy 2014, 115, 103-115.

3. Yang, H.; Wei, Z.; Chengzhi, L. Optimal design and techno-economic analysis of a hybrid solar-wind power generation system. Appl. Energy 2009, 86, 163-169.

4. Goundar, J.N.; Ahmed, M.R. Design of a horizontal axis tidal current turbine. Appl. Energy 2013, $111,161-174$.

5. Hsiao, F.-B.; Bai, C.-J.; Chong, W.-T. The performance test of three different horizontal axis wind turbine (HAWT) blade shapes using experimental and numerical methods. Energies 2013, 6, 2784-2803.

6. Lee, J.H.; Park, S.; Kim, D.H.; Rhee, S.H.; Kim, M.-C. Computational methods for performance analysis of horizontal axis tidal stream turbines. Appl. Energy 2012, 98, 512-523.

7. Krogstad, P.A.; Lund, J.A. An experimental and numerical study of the perofrmance of a model turbine. WInd Energy 2012, 15, 443-457. 
8. Martínez, J.; Bernabini, L.; Probst, O.; Rodríguez, C. An improved BEM model for the power curve prediction of stall-regulated wind turbines. Wind Energy 2005, 8, 385-402.

9. Lanzafame, R.; Messina, M. Fluid dynamics wind turbine design: Critical analysis, optimization and application of BEM theory. Renew. Energy 2007, 32, 2291-2305.

10. Dai, J.C.; Hu, Y.P.; Liu, D.S.; Long, X. Aerodynamic loads calculation and analysis for large scale wind turbine based on combining BEM modified theory with dynamic stall model. Renew. Energy 2011, 36, 1095-1104.

11. Hirahara, H.; Hossain, M.Z.; Kawahashi, M.; Nonomura, Y. Testing basic performance of a very small wind turbine designed for multi-purposes. Renew. Energy 2005, 30, 1279-1297.

12. Kishinami, K.; Taniguchi, H.; Suzuki, J.; Ibano, H.; Kazunou, T.; Turuhami, M. Theoretical and experimental study on the aerodynamic characteristics of a horizontal axis wind turbine. Energy 2005, 30, 2089-2100.

13. Bottasso, C.L.; Campagnolo, F.; Petrović, V. Wind tunnel testing of scaled wind turbine models: Beyond aerodynamics. J. Wind Eng. Ind. Aerodyn. 2014, 127, 11-28.

14. Sheng, W.; Galbraith, R.A.M.; Coton, F.N. On the S809 airfoil's unsteady aerodynamic characteristics. Wind Energy 2009, 12, 752-767.

15. Vermeer, L.J.; Sørensen, J.N.; Crespo, A. Wind turbine wake aerodynamics. Progr. Aerosp. Sci. 2003, 39, 467-510.

16. Hansen, A.D.; Sørensen, P.; Iov, F.; Blaabjerg, F. Control of variable speed wind turbines with DFIGs. Wind Eng. 2004, 28, 411-434.

17. Lei, Y.; Mullane, A.; Lightbody, G.; Yacamini, R. Modeling of the wind turbine with a doubly fed induction generator for grid integration studies. IEEE Tran. Energy Convers. 2006, 21, 257-264.

18. González, L.G.; Figueres, E.; Garcerá, G.; Carranza, O. Maximum-power-point tracking with reduced mechanical stress applied to wind-energy-conversion-systems. Appl. Energy 2010, 87, 2304-2312.

19. Carranza, O.; Figueres, E.; Garcerá, G.; Gonzalez-Medina, R. Analysis of the control structure of wind energy generation systems based on a permanent magnet synchronous generator. Appl. Energy 2013, 103, 522-538.

20. Arroyo, A.; Manana, M.; Gomez, C.; Fernandez, I.; Delgado, F.; Zobaa, A.F. A methodology for the low-cost optimisation of small wind turbine performance. Appl. Energy 2013, 104, 1-9.

21. Amrouche, B.; Guessoum, A.; Belhamel, M. A simple behavioural model for solar module electric characteristics based on the first order system step response for MPPT study and comparison. Appl. Energy 2012, 91, 395-404.

22. Brahmi, J.; Krichen, L.; Ouali, A. A comparative study between three sensorless control strategies for PMSG in wind energy conversion system. Appl. Energy 2009, 86, 1565-1573.

23. Song, Z.; Xia, C.; Shi, T. Assessing transient response of DFIG based wind turbines during voltage dips regarding main flux saturation and rotor deep-bar effect. Appl. Energy 2010, 87, 3283-3293.

24. Rahimi, M.; Parniani, M. Grid-fault ride-through analysis and control of wind turbines with doubly fed induction generators. Electr. Power Syst. Res. 2010, 80, 184-195.

25. Mahmoudi, A.; Rahim, N.A.; Ping, H.W. Axial-flux permanent-magnet motor design for electric vehicle direct drive using sizing equation and finite element analysis. Prog. Electromagn. Res. 2012, 122, 467-496. 
26. Jung, T.-U. Electromagnetic design analysis and performance improvement of axial field permanent magnet generator for small wind turbine. J. Appl. Phys. 2012, 111, $07 \mathrm{E} 708$.

27. Manwell, J.F.; McGowan, J.G.; Rogers, A.L. Wind Energy Explained-Theory, Design and Application, 2nd ed.; John Wiley \& Sons Ltd.: Chichester, West Sussex, UK, 2010.

28. Barlow, J.B.; Rae, W.H., Jr.; POPE, A. Low-Speed Wind Tunnel Testing, 3rd ed.; Wiley-Interscience: New York, NY, USA, 1999.

29. Viterna, L.A.; Corrigan, R.D. Fixed pitch rotor performance of large horizontal axis wind turbines. In Proceedings of the DOE/NASA Workshop on Large Horizontal Axis Wind Turbine, Cleveland, OH, USA, 28-30 July 1981; Volume 15, pp. 69-85.

30. Chan, T.F.; Lai, L.L. An Axial-flux permanent-magnet synchronous generator for a direct-coupled wind-turbine system. IEEE Trans. Energy Convers. 2007, 22, 86-94.

31. Spera, D.A. Wind Turbine Technology: Fundamental Concepts of Wind Turbine Engineering; ASME Press: New York, NY, USA, 1994.

32. Chen, T.Y.; Liou, L.R. Blockage corrections in wind tunnel tests of small horizontal-axis wind turbines. Exp. Therm. Fluid Sci. 2011, 35, 565-569.

33. Simms, D.; Schreck, S.; Hand, M.; Fingersh, L.J. NREL Unsteady Aerodynamics Experiment in the NASA-Ames Wind Tunnel: Comparison of Predictions to Measurements; BiblioGov: Golden, CO, USA, 2001.

(C) 2014 by the authors; licensee MDPI, Basel, Switzerland. This article is an open access article distributed under the terms and conditions of the Creative Commons Attribution license (http://creativecommons.org/licenses/by/4.0/). 